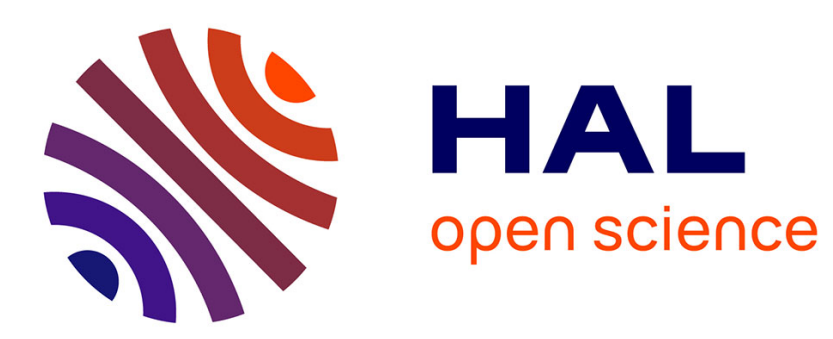

\title{
Structures and transistor properties of extended and unsymmetrical birhodanines
}

Y. Sumimoto, K. Iijima, D. Yoo, T. Kawamoto, Y. Le Gal, D. Lorcy, T. Mori

\section{To cite this version:}

Y. Sumimoto, K. Iijima, D. Yoo, T. Kawamoto, Y. Le Gal, et al.. Structures and transistor properties of extended and unsymmetrical birhodanines. CrystEngComm, 2020, 22 (41), pp.6920-6926. 10.1039/d0ce01133a . hal-03003356

\section{HAL Id: hal-03003356 https://hal.science/hal-03003356}

Submitted on 18 Nov 2020

HAL is a multi-disciplinary open access archive for the deposit and dissemination of scientific research documents, whether they are published or not. The documents may come from teaching and research institutions in France or abroad, or from public or private research centers.
L'archive ouverte pluridisciplinaire HAL, est destinée au dépôt et à la diffusion de documents scientifiques de niveau recherche, publiés ou non, émanant des établissements d'enseignement et de recherche français ou étrangers, des laboratoires publics ou privés. 


\title{
Structures and transistor properties of extended and unsymmetrical birhodanines $\dagger$
}

\author{
and Takehiko Mori*a

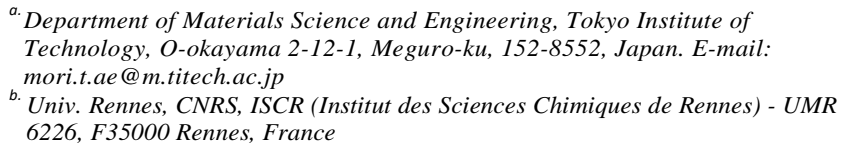

Yuji Sumimoto, ${ }^{\mathrm{a}}$ Kodai lijima, ${ }^{\mathrm{a}}$ Dongho Yoo, ${ }^{\mathrm{a}}$ Tadashi Kawamoto, ${ }^{\mathrm{a}}$ Yann Le Gal, ${ }^{\mathrm{b}}$ Dominique Lorcy,

Birhodanines exhibit n-channel transistor properties with air stability. In this work, birhodanines with extended skeletons are investigated, in which a phenylene or quinoidal moiety is inserted in the central C $=\mathrm{C}$ part. We have also prepared $\mathrm{N}$-phenyl and unsymmetrically $\mathrm{N}$-substituted derivatives, including an unsubstituted $\mathrm{N}-\mathrm{H}$ part. These compounds show n-channel transistor properties. In contrast to the herringbone structure of the parent compounds, the phenylene and phenyl compounds have stacking structures. The phenylene substitution decreases the acceptor ability, whereas quinoidal substitution improves the acceptor ability and air stability of the transistors. The $\mathrm{N}$-H derivative has a Z-form, suggesting contribution of the enolic form, and unsymmetrically $N$-substituted derivatives have double-layer structures with ordered alkyl chains.

\section{Introduction}

Considerable attention has been paid to organic semiconductors used in organic transistors. ${ }^{1} \quad$ Although various high-performance materials have been proposed, ${ }^{2}$ there still remains a lot of room in nchannel materials showing air-stable operation. ${ }^{1}$ Previously, we have reported air-stable n-channel transistor properties in 5,5'bithiazolidinylidene-2,4,2',4'-tetrathiones (Scheme 1 , SS- $\boldsymbol{R}$ ). ${ }^{3,4}$ These materials are obtained in the course of developing singlecomponent organic metals, ${ }^{5}$ but show strong acceptor ability with the lowest unoccupied molecular orbitals (LUMO) around $-4.2 \mathrm{eV} .{ }^{4}$ The $R$ = ethyl and propyl compounds (SS-Et and SS-Pr) exhibit excellently air-stable n-channel transistor characteristics. ${ }^{3,4}$ Materials with longer alkyl chains show reduced performance, ${ }^{6}$ though single-crystal transistors of the pentyl compound exhibit a mobility of $1.1 \mathrm{~cm}^{2} \mathrm{~V}^{-1} \mathrm{~s}^{-1}$. $\quad$ In addition to these tetrathione derivatives, the 2,2'-dione-4,4'-dithione derivatives (OS- $\boldsymbol{R}$ ) are regarded as a dimer of rhodanine, which is a well-known electron-deficient unit. ${ }^{8}$ Birhodanine is easily prepared by reacting alkyl amine, carbon disulfide, and dimethyl acetylene dicarboxylate for several minutes at room temperature. ${ }^{4}$ The

† Electronic Supplementary Information (ESI) available: Additional information for preparative details, structure analysis, devices fabrication, AFM images, and transistor characteristics. CCDC 2017521-2017527. For ESI and crystallographic data in CIF or other electronic format see DOI:

$\ddagger$ Present address: Department of Chemical Engineering and Center for Advanced Soft Electronics, Pohang University of Science and Technology, 77 Cheongam-Ro, Nam-Gu, Pohang 37673, Korea.
LUMO level of OS- $\boldsymbol{R}$ is located around $-3.8 \mathrm{eV},{ }^{4}$ which is a weaker electron acceptor than SS- $\boldsymbol{R}$. SS- $\boldsymbol{R}$ has a stacking structure, whereas OS- $\boldsymbol{R}$ has a herringbone structure. OS- $\boldsymbol{R}$ shows similar transistor properties, though the performance and air stability are slightly reduced.

As an element of organic conductors, various $\pi$-extended molecules have been investigated. ${ }^{9}$ In particular, introduction of a quinoidal unit is a versatile tool to improve the donor/acceptor ability. ${ }^{10}$ In addition, even superconductivity has been found in vinylogous bis-fused tetrathiafulvalene. ${ }^{11}$ Inspired by these findings, we have prepared $\pi$-extended birhodanines (Scheme 1). In 1, a phenylene unit is inserted in the central $\mathrm{C}=\mathrm{C}$ part, ${ }^{12}$ whereas in $\mathbf{2}$ a quinoidal part is introduced. ${ }^{13}$ We have also developed a synthetic route to $N$-phenyl substituted compound, OS-Ph, and unsymmetrically $N$-substituted derivatives, OS- $\boldsymbol{R} \boldsymbol{R}^{\prime}$ containing different alky chains as well as an unsubstituted $\mathrm{N}$-H part.

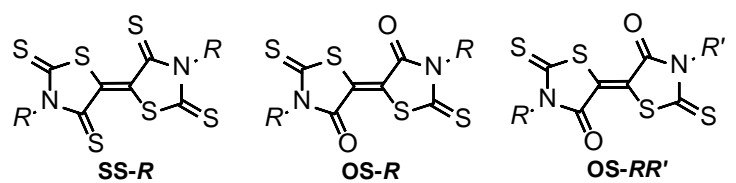

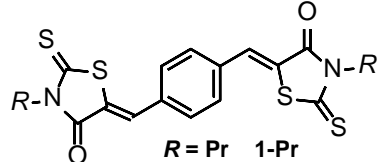

$\mathrm{Ph}$ 1-Ph

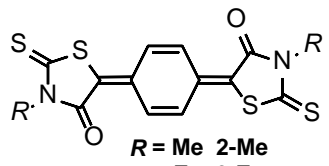

Et 2-Et
Scheme 1. Molecular structures of SS-R, OS- $\boldsymbol{R}$, and the extended derivatives. 
Table 1. Reduction potentials, energy levels, and optical gaps.

\begin{tabular}{lccccc}
\hline & $E_{\text {red }}(\mathrm{V})$ & $E_{\text {LUMO }}(\mathrm{eV})^{\mathrm{a}}$ & $\lambda_{\text {edge }}(\mathrm{nm})^{\mathrm{b}}$ & ${\text { Optical gap }(\mathrm{eV})^{\mathrm{b}}}$ & $E_{\text {Hомо }}(\mathrm{eV})^{\mathrm{a}}$ \\
\hline OS-Et & \\
1-Pr & -1.00 & $-3.80(-3.80)$ & $482(438)$ & $2.57(2.8)$ & $-6.37(-6.44)$ \\
1-Ph & -1.17 & $-3.63(-3.63)$ & $472(508)$ & $2.63(2.4)$ & $-6.26(-6.25)$ \\
2-Me & -1.24 & $-3.56(-3.56)$ & 472 & 2.63 & $-6.19(-6.28)$ \\
2-Et & -0.41 & -4.21 & 624 & 1.99 & -6.20 \\
2-Pr & -0.39 & -4.23 & 621 & 2.00 & -6.23 \\
2-Bu & -0.40 & -4.20 & 607 & 2.04 & -6.24 \\
2-Ph & -0.40 & -4.20 & 617 & 2.00 & -6.20 \\
OS-Ph & -0.39 & -4.20 & 623 & 1.99 & -6.19 \\
OS-EtH & -0.68 & $-3.95(-3.80)$ & 508 & 2.53 & $-6.48(-6.34)$ \\
OS-BuH & -0.64 & -3.98 & 508 & 2.44 & -6.42 \\
OS-EtMe & -0.62 & $-4.00(-3.88)$ & 514 & 2.41 & $-6.41(-6.72)$ \\
OS-PrMe & -0.96 & $-3.84(-3.61)$ & 493 & 2.51 & $-6.35(-6.39)$ \\
OS-BuMe & -0.96 & -3.84 & 493 & 2.51 & -6.35 \\
OS-PrEt & -0.96 & $-3.84(-3.81)$ & 487 & 2.54 & $-6.38(-6.48)$ \\
\hline
\end{tabular}

${ }^{a}$ The LUMO levels were estimated from the first reduction potentials by assuming the reference energy level of ferrocene/ferrocenium to be $4.8 \mathrm{eV}$ from the vacuum level. ${ }^{17}$ The HOMO levels were obtained by subtracting the optical gaps from the LUMO levels. The values in the parentheses were calculated by using the ADF software with the B3LYP* functional and TZP basis set. ${ }^{18}{ }^{b}$ The values in the parentheses were from absorption of the thin films.

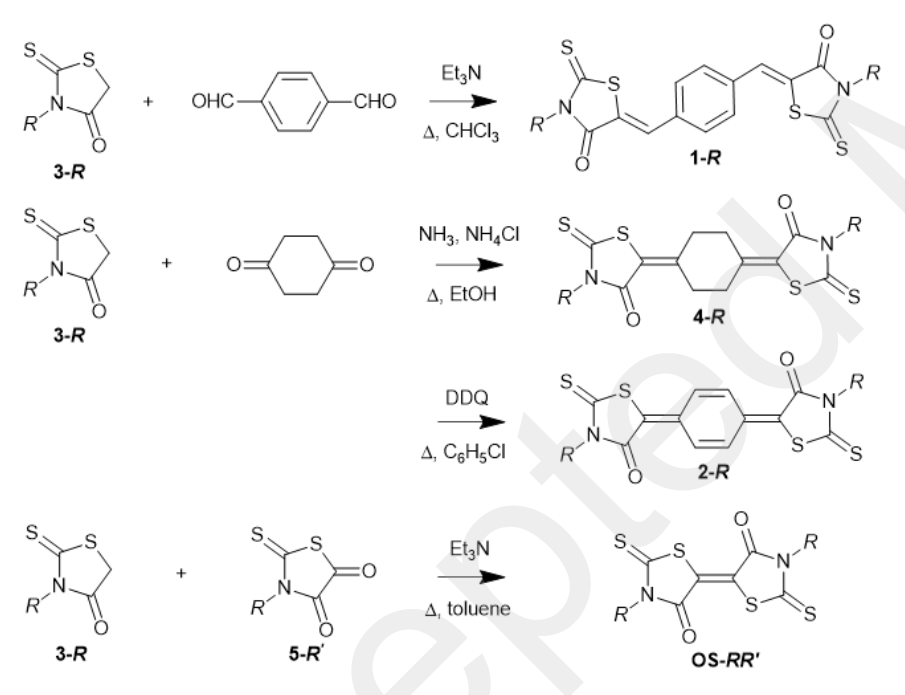

Scheme 2. Preparation of 1-R, 2-R, and OS-RR'.

\section{Results and discussion}

\section{Preparation}

$n$-Propyl and phenyl rhodanines $\mathbf{3}-\boldsymbol{R}$ were obtained from the dithiocarbamate and chloroacetic acid. ${ }^{14}$ Similarly to the previous reactions, ${ }^{12,15}$ the rhodanines were reacted with terephthalaldehyde in the presence of triethylamine to afford $\mathbf{1 - R}$ (Scheme 2). In order to prepare $\mathbf{2}-\boldsymbol{R}$, rhodanines $\mathbf{3}-\boldsymbol{R}(R=\mathrm{Pr}, \mathrm{Bu}$, and $\mathrm{Ph})$ were reacted with 1,4-cyclohexanedione in the presence of ammonia. ${ }^{13}$ The resulting 4- $\boldsymbol{R}$ was reacted with 2,3-dichloro-5,6-dicyano-p-
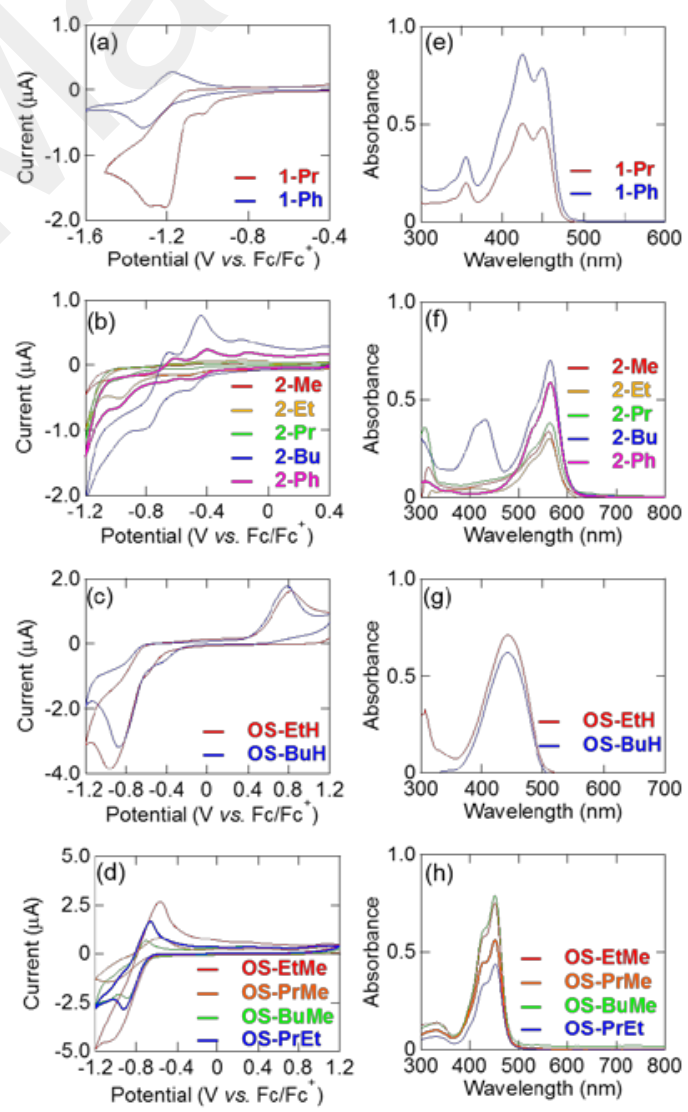

Fig. 1. Cyclic voltammograms of (a) $\mathbf{1}-\boldsymbol{R}$, (b) $\mathbf{2}-\boldsymbol{R}$, (c) OS- $\boldsymbol{R} \mathbf{H}$, and (d) OS- $\boldsymbol{R} \boldsymbol{R}^{\prime}$, measured in $n-\mathrm{Bu}_{4} \mathrm{~N} \cdot \mathrm{PF}_{6} / \mathrm{CH}_{2} \mathrm{Cl}_{2}(50 \mathrm{mV} \mathrm{s})$. Normalized absorption spectra of (e) 1-R, (f) 2-R, (g) OS- $\boldsymbol{R H}$, and (h) OS- $\boldsymbol{R}^{\prime}$, measured in DMF. 
Table 2. Crystallographic data.

\begin{tabular}{|c|c|c|c|c|c|c|c|}
\hline & 1-Pr & 1-Ph & OS-Ph & OS-BuH & OS-EtMe & OS-BuMe & OS-PrEt \\
\hline Formula & $\mathrm{C}_{20} \mathrm{H}_{20} \mathrm{~N}_{2} \mathrm{O}_{2} \mathrm{~S}_{4}$ & $\mathrm{C}_{22} \mathrm{H}_{18} \mathrm{~N}_{2} \mathrm{O}_{2} \mathrm{~S}_{4}$ & $\mathrm{C}_{18} \mathrm{H}_{10} \mathrm{~N}_{2} \mathrm{O}_{2} \mathrm{~S}_{4}$ & $\mathrm{C}_{10} \mathrm{H}_{10} \mathrm{~N}_{2} \mathrm{O}_{2} \mathrm{~S}_{4}$ & $\mathrm{C}_{9} \mathrm{H}_{8} \mathrm{~N}_{2} \mathrm{O}_{2} \mathrm{~S}_{4}$ & $\mathrm{C}_{11} \mathrm{H}_{12} \mathrm{~N}_{2} \mathrm{O}_{2} \mathrm{~S}_{4}$ & $\mathrm{C}_{11} \mathrm{H}_{12} \mathrm{~N}_{2} \mathrm{O}_{2} \mathrm{~S}_{4}$ \\
\hline Formula weight & 448.63 & 516.66 & 414.53 & 318.44 & 304.41 & 332.47 & 332.47 \\
\hline Crystal System & Triclinic & Monoclinic & Triclinic & Monoclinic & Monoclinic & Monoclinic & Monoclinic \\
\hline Space Group & $P-1$ & $P 2_{1} / n$ & $P-1$ & $P 2_{1} / n$ & $P 2_{1} / C$ & $P 2_{1} / c$ & $P 2_{1} / C$ \\
\hline Shape & Orange prism & Orange needle & Orange plate & Orange needle & Orange plate & Orange plate & Orange plate \\
\hline$a(\AA)$ & $5.868(4)$ & $12.6138(4)$ & $4.8107(4)$ & $14.3245(9)$ & $11.429(4)$ & $26.578(7)$ & $25.445(6)$ \\
\hline$b(\AA)$ & $9.531(6)$ & $5.52905(16)$ & $9.0732(6)$ & 4.9698(3) & $7.888(3)$ & 7.813(3) & $8.045(2)$ \\
\hline$c(\AA)$ & $10.618(6)$ & $16.8453(5)$ & $11.0382(6)$ & $19.9041(12)$ & 7.254(3) & $7.2475(12)$ & $7.101(2)$ \\
\hline$\alpha$ (deg.) & $107.56(5)$ & 90 & 108.240(3) & 90 & 90 & 90 & 90 \\
\hline$\beta$ (deg.) & $93.87(6)$ & $100.868(2)$ & 98.143(4) & 106.593(3) & $99.20(3)$ & $93.773(17)$ & $93.45(2)$ \\
\hline$\gamma$ (deg.) & $106.20(6)$ & 90 & $96.693(4)$ & 90 & 90 & 90 & 90 \\
\hline$V\left(\AA^{3}\right)$ & $536.2(7)$ & 1153.76(6) & $446.30(5)$ & $1357.94(14)$ & $645.6(7)$ & $1501.7(7)$ & $1451.0(9)$ \\
\hline Z-value & 1 & 2 & 1 & 4 & 2 & 4 & 4 \\
\hline$T(\mathrm{~K})$ & 295 & 275 & 275 & 274 & 297 & 297 & 297 \\
\hline$D_{\text {calc }}\left(\mathrm{g} \mathrm{cm}^{-3}\right)$ & 1.389 & 1.487 & 1.542 & 1.557 & 1.566 & 1.470 & 1.522 \\
\hline Total reflns. & 3667 & 12276 & 4892 & 13966 & 1461 & 3359 & 3177 \\
\hline $\begin{array}{l}\text { Unique reflns. } \\
\qquad\left(R_{\text {int }}\right)\end{array}$ & $\begin{array}{c}3131 \\
(0.0563)\end{array}$ & $\begin{array}{c}2098 \\
(0.0890)\end{array}$ & $\begin{array}{c}1611 \\
(0.1151)\end{array}$ & $\begin{array}{c}2393 \\
(0.1548)\end{array}$ & $\begin{array}{c}1144 \\
(0.0950)\end{array}$ & $\begin{array}{c}2727 \\
(0.0196)\end{array}$ & $\begin{array}{c}2572 \\
(0.0664)\end{array}$ \\
\hline$R_{1}\left[F^{2}>2 \sigma\left(F^{2}\right)\right]$ & 0.0447 & 0.1024 & 0.0796 & 0.0740 & 0.0563 & 0.0431 & 0.0447 \\
\hline $\begin{array}{c}w R_{2} \text { [All } \\
\text { reflns.] }\end{array}$ & 0.1240 & 0.3367 & 0.2371 & 0.2123 & 0.1713 & 0.1402 & 0.1402 \\
\hline GOF & 0.986 & 1.235 & 0.972 & 0.876 & 1.034 & 1.018 & 1.014 \\
\hline $\begin{array}{l}\text { Interplanar } \\
\text { spacing }(\AA)\end{array}$ & 3.587 & 3.410 & 3.550 & 3.404 & 3.157 & 3.120 & 3.273 \\
\hline
\end{tabular}

benzoquinone (DDQ) to give $\mathbf{2}-\boldsymbol{R}$. OS-Ph was not obtained by the direct reaction of aniline with carbon disulfide and dimethyl acetylene dicarboxylate. ${ }^{4}$ Instead, rhodanine 3-Ph was condensed with isatine 5-Ph to afford $\mathbf{O S}-\mathbf{P h}{ }^{16}$ The same reaction was applied to prepare unsymmetrically substituted OS-RR' (RR' = EtMe, PrMe, BuMe, and PrEt). Using this route, we can also obtain $N$ unsubstituted compounds $\left(R R^{\prime}=\mathrm{EtH}\right.$ and $\left.\mathrm{BuH}\right)$. Among these compounds, 1-Pr, 2-Pr, and unsymmetrical compounds are new compounds.

\section{Electrochemical properties}

Cyclic voltammetry of these compounds shows clear reduction waves (Fig. 1), from which the LUMO levels are estimated as listed in Table 1. Compound $\mathbf{1}$ is a weaker acceptor than the parent OS- $\boldsymbol{R}$ due to the insertion of a phenyl ring. By contrast, $\mathbf{2}$ is a stronger acceptor than OS-R in agreement with the quinoidal structure, which is as strong as SS-R. ${ }^{4}$ Optical gaps of $\mathbf{1}$ are slightly larger than OS$\boldsymbol{R}$, whereas those of $\mathbf{2}$ are significantly smaller than OS-R. As a result, the LUMO levels largely depend on the $\pi$-extension manner, though the highest occupied molecular orbital (HOMO) levels of these compounds are approximately the same.

OS-Ph and OS-RH are slightly stronger acceptors than OS-Et, indicating the alkyl groups are weakening the acceptor ability. The reduction of $\mathbf{O S}-\mathbf{R H}$ is, however, somewhat irreversible.

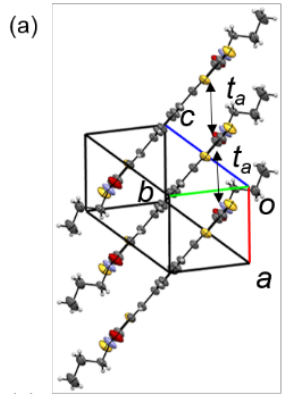

(c)

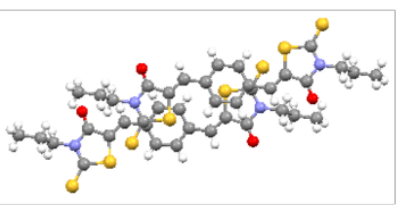

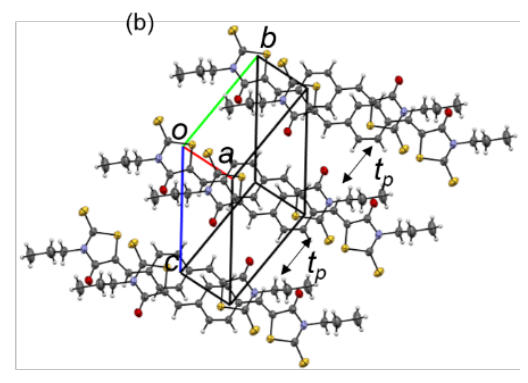

(d)

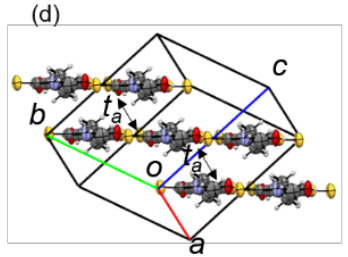

Fig. 2. Crystal structure of 1-Pr, (a) viewed along the molecular short axis, (b) viewed perpendicular to molecular plane, (c) molecular overlap mode, and (d) viewed along the molecular long axis. Transfer integrals of the LUMO-LUMO interactions are $a=2.3$ and $p=0.1 \mathrm{meV}$. 


\section{Crystal structures}

X-ray single crystal structure analyses were carried out for 1Pr, 1-Ph, OS-Ph, OS-BuH, OS-EtMe, OS-BuMe, and OSPrEt. The crystal data are listed in Table 2.

1-Pr is a planar molecule except for the propyl chains (Fig. 2). A molecule is located on an inversion center, and a half molecule is crystallographically independent. The molecules are uniformly stacked along the $a$ axis (Fig. 2(a)) with a large tilt angle $\left(45^{\circ}\right)$ of the molecular long axis from the stacking $(a)$ axis. The molecular long axis does not correspond to neither the $b$ or $c$ axis (Fig. 2(b)). In the stack, the molecules are largely displaced both along the molecular long and short axes (Fig. 2(c)), in which a thiazol sulfur is located approximately on the top of the central phenylene ring. The molecules are stacked with a short axis displacement similar to SS-R crystals (Fig. 2(d)). ${ }^{4}$ There are short S-S contacts, 3.64 and $3.94 \AA$ along the stack. The intrachain transfer is comparatively small, but the interchain transfers are even smaller (Fig. 2).
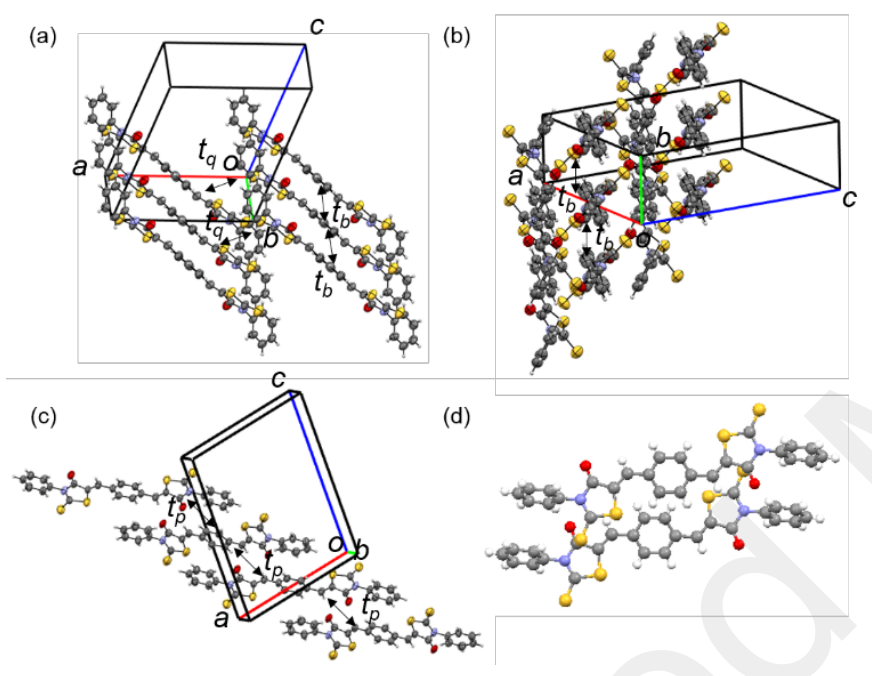

Fig. 3. Crystal structure of 1-Ph, (a) viewed along the molecular short axis, (b) viewed along the molecular long axis, (c) viewed along the $b$ axis, and (d) molecular overlap mode. Transfer integrals of the LUMO-LUMO interactions are $b=51.3, p=0.4$, and $q=12.9 \mathrm{meV}$. (a)

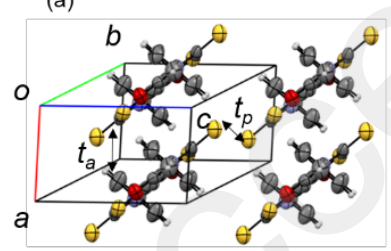

(b)

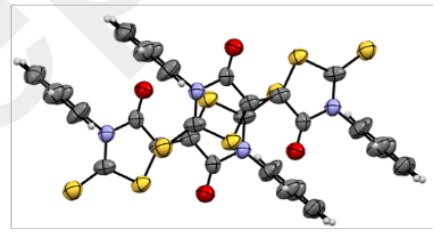

Fig. 4. Crystal structure of OS-Ph, (a) viewed along the molecular long axis, and (b) molecular overlap mode. Transfer integrals of the LUMO-LUMO interactions are $a=140.9$ and $p=10.2 \mathrm{meV}$.

1-Ph has a planar core, though the terminal phenyl groups are tilted by $71.9^{\circ}$ from the core part (Fig. 3). A molecule is located on an inversion center, and a half molecule is crystallographically independent. The molecules are uniformly stacked along the $b$ axis (Fig. 3(a)), where the molecular long axes are $26^{\circ}$ tilted from the stacking $(b)$ axis. Owing to the monoclinic symmetry, molecules in the adjacent stacks are tilted in the opposite directions (Fig. 3(b)), where the interchain contacts run along the $a+c$ axis (Fig. 3(c)). In the stack, the molecules are more largely displaced both along the molecular long and short axes (Fig. 3(d)). There are short S-S contacts, 3.63 and $4.04 \AA$, and significant intra- and inter-chain transfer integrals (Fig. 3).

OS-Ph has a planar core, though the terminal phenyl groups are tilted by $78.4^{\circ}$ from the core part (Fig. 4). A half molecule is crystallographically independent, and a molecule is located on an inversion center. Then, all molecules are parallel to each other, and stacked along the $a$ axis (Fig. 4(a)). Accordingly, the packing pattern resembles SS-R rather than the herringbone OS- $\boldsymbol{R}$. There are S-S contacts, 3.82, 4.01 and $4.02 \AA$ along the stack, and a considerable intrachain transfer integral (Fig. 4). (a)

(c)
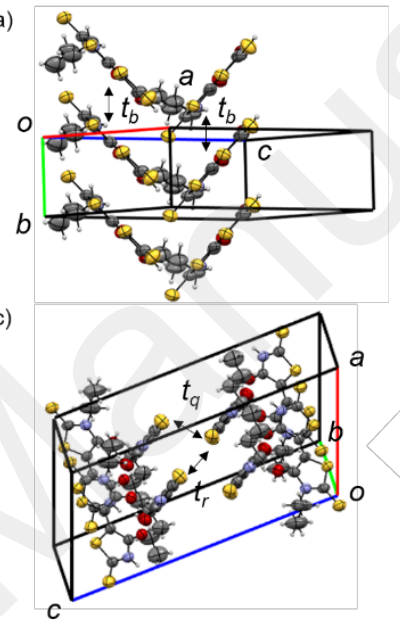

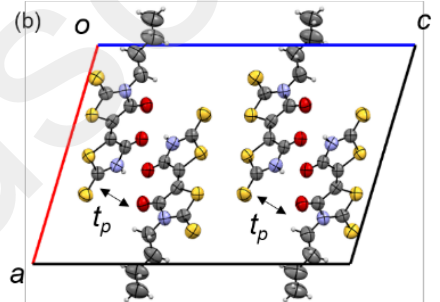

(d)

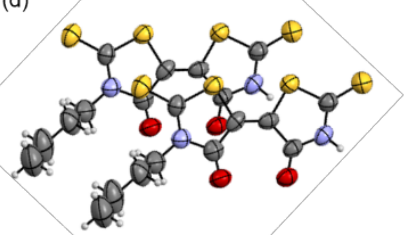

Fig. 5 .

Crystal structure

of OS-BuH, (a) molecular overlap mode, (b) viewed along the $b$ axis, (c) viewed along the molecular short axis, and (d) viewed along the molecular long axis. Transfer integrals of the LUMO-LUMO interactions are $b=49.9$, and $p=19.1, q=5.3$, and $r=12.7 \mathrm{meV}$.

As shown in Fig. 5, unsymmetrically substituted OS-BuH has a planar core (Figs. 5(a) and (b)), but the sulfur atoms are located on the same side ( $Z$-form). Since the $\mathrm{O} \cdots \mathrm{O}$ distance is as small as $2.748 \AA$, we have to suspect hydrogen bonding, where the nitrogen $\mathrm{H}$ moves to $\mathrm{O}$ (Fig. S2). Although the ketone form is preferable to the enolic form in the crystal structure analysis, the contribution of the enolic form may be related to the $Z$-configuration.

The molecules are uniformly stacked along the $b$ axis (Fig. 5(c)). The molecular long axes are parallel to the $a$ axis (Fig. 5(b)), and the interchain interactions are along the $c$ axis. In the stack, the molecules are largely displaced both along the molecular long and short axes (Fig. 5(a)); this overlap mode is very similar to SS-R. ${ }^{4}$ The tilt angle of the molecular long axis from the stacking $(b)$ axis is $33^{\circ}$ (Fig. 5(c)), but every two columns are tilted in the opposite directions (Fig. 5(d)). Accordingly, molecules in the central two columns in Figs. 5(b) and (d) are parallel to each other; this part has the same ( $\beta$ "like) structure as SS-R. There are many $S-S$ contacts in this 
interstack direction, 3.73, 3.78, 3.84, and $3.98 \AA$ between these parallel molecules because the sulfur atoms are aligned in the same side. These are shorter than the intrastack $\mathrm{S}-\mathrm{S}$ contacts of 3.94 and $4.06 \AA$. Transfer in this intercolumnar direction $(p)$ is considerably large, and a two-dimensional network is formed.

OS-EtMe, OS-BuMe, and OS-PrEt have herringbone structures with the same space group (Fig. 6(a)), but are not entirely isostructural. OS-EtMe has a single layer structure along the $a$ axis, whereas OS-BuMe and OS-PrEt have a double layer structure (Fig. 6(b)). This is because the methyl and ethyl groups in OS-EtMe are disordered, but other alkyl groups are ordered. In the symmetrical OS- $\boldsymbol{R}$, the layers are alternately tilted in even $R$, but entirely parallel in odd $R$. In OS-BuMe and OS-PrEt, all layers are parallel, but still make a double layer structure because the longer alkyl chains are oriented to the same interlayer spacing. Since the dihedral angle tends to increase with increasing the alkyl chain, ${ }^{4}$ the observed dihedral angles (Table 3) are in the similar level to the symmetrical molecules. In contrast to the symmetrical OS-R, $t_{\mathrm{c}}$ is larger than the diagonal transfer integrals, $t_{\mathrm{p}}$ and $t_{\mathrm{q}}$, but forms a balanced two-dimensional network.
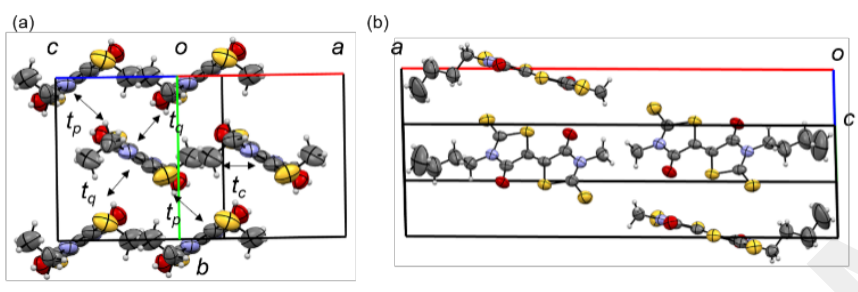

Fig. 6. (a) Crystal structure of OS-EtMe viewed along the molecular long axis. (b) Crystal structure of OS-BuMe viewed along the molecular short axis.

Table 3. Dihedral angles and transfer integrals (meV) in OS-RR'.

\begin{tabular}{lccccc}
\hline & $\begin{array}{c}\text { Dihedral } \\
\text { angle }\end{array}$ & $t_{c}$ & $t_{p}$ & $t_{q}$ & $\begin{array}{c}\text { Tilt } \\
\text { angle }\end{array}$ \\
\hline OS-MeEt & $62^{\circ}$ & 31.4 & 17.1 & 18.0 & $17^{\circ}$ \\
OS-MeBu & $61^{\circ}$ & 37.8 & 20.1 & 22.3 & $17^{\circ}$ \\
OS-EtPr & $66^{\circ}$ & 49.1 & 9.18 & 11.4 & $19^{\circ}$ \\
\hline
\end{tabular}

\section{Thin film properties}

Evaporated films of 1-Pr and 1-Ph show X-ray diffraction (XRD) peaks (Fig. 7(a)). However, $d=19.8 \AA$ of 1-Pr does not agree with the crystal lattice (Table 2). Since the molecular length is estimated to be $l=20.8 \AA$ from the crystal structure, the tilt angle $\theta$ in the thin film is expected to be $\theta=19.8^{\circ}$ by using $l=d / \cos \theta$. The thin film structure is potentially different from the single-crystal structure. For 1-Ph, $d=14.2 \AA$ is not far from $a+b=13.8 \AA$, corresponding to the molecular long axis (Fig. $3(c)$ ). Then, the thin film structure is not largely different from the crystal structure.

XRD of 2-R ( $R=\mathrm{Me}, \mathrm{Et}, \mathrm{Bu}$, and $\mathrm{Ph})$ exhibit peaks at $d=12.7$, 13.0, 17.8, and 19.2 $\AA$, respectively (Fig. 7(b)); these $d$ values approximately correspond to the molecular lengths. Although crystal structures of these compounds have not been determined due to the comparatively poor crystallinity, these compounds construct ordinary layer structures.

The unsymmetrical OS- $\boldsymbol{R} \boldsymbol{R}^{\prime}$ show sharp XRD peaks with many higher-order peaks (Figs. 7(c) and (d)). The peaks around $4^{\circ}$ in OSEtH and OS-BuH correspond to $d=20.1$ and $23.5 \AA$, respectively, indicating the double layer structures. The peaks around $8^{\circ}$ in OSEtMe, OS-PrMe, OS-BuMe, and OS-PrEt correspond to 11.3, 12.1, 13.3, 13.6 $\AA$, in agreement with the crystal $a$ axis (Table 2). Then, the molecules are tilted from the substrate normal by an angle of $17 \sim 19^{\circ}$ (Table 3), which are in the same order as $18 \sim 19^{\circ}$ in the symmetrical molecules. ${ }^{4}$ OS-BuMe shows a clear peak at $4^{\circ}$, indicating the double layer structure. The low-angle peak is less obvious in other OS-RR'.
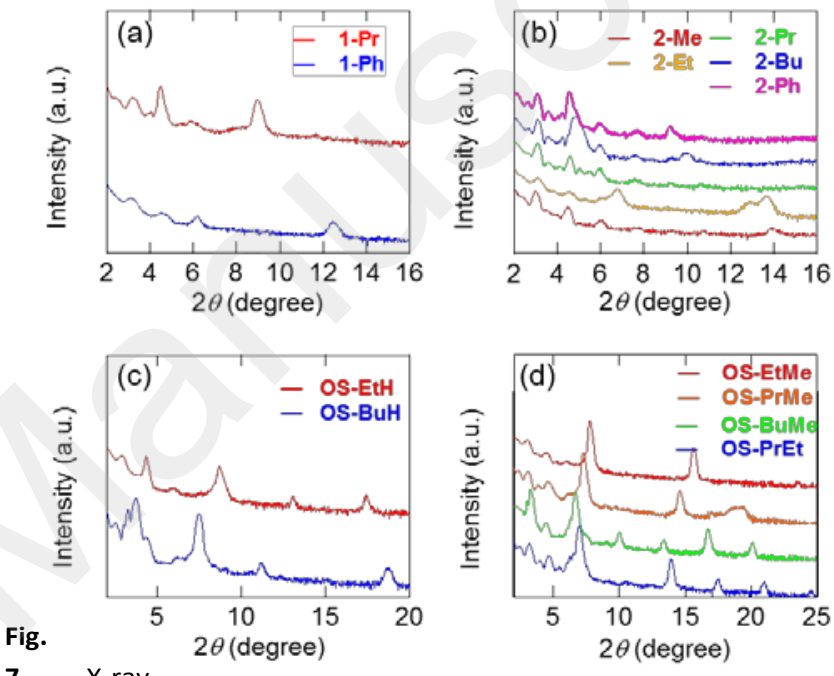

7. X-ray

diffraction pattern of (a) 1- $\boldsymbol{R}$, (b) 2-R, (c) OS- $\boldsymbol{R} \mathbf{H}$, and (d) OS- $\boldsymbol{R} \boldsymbol{R}^{\prime}$.

Atomic force microscopic (AFM) images show highly crystalline morphology (Fig. 8). 1-Pr shows comparatively loose packing of large crystals (Fig. 8(a)). OS-RR' shows large crystals, which are consistent with the sharp XRD peaks, but large inter-grain space may be related to the transistor performance. 
Table 4. Characteristics of thin-film transistors.

\begin{tabular}{|c|c|c|c|c|c|}
\hline & & $\mu_{\max }\left(\mathrm{cm}^{2} \mathrm{~V}^{-1} \mathrm{~s}^{-1}\right)$ & $\mu_{\text {ave }}\left(\mathrm{cm}^{2} \mathrm{~V}^{-1} \mathrm{~s}^{-1}\right)$ & $V_{\text {th }}(\mathrm{V})$ & On/off ratio \\
\hline \multirow[t]{2}{*}{ 1-Ph } & under vacuum & 0.019 & 0.013 & 76 & $7 \times 10^{5}$ \\
\hline & in air & $1.4 \times 10^{-4}$ & $9.8 \times 10^{-5}$ & 153 & $3 \times 10^{4}$ \\
\hline 2-Me & under vacuum & $5.0 \times 10^{-5}$ & $3.4 \times 10^{-5}$ & -4 & $6 \times 10^{2}$ \\
\hline \multirow[t]{2}{*}{ 2-Et } & under vacuum & 0.041 & 0.038 & 4 & $2 \times 10^{4}$ \\
\hline & in air & 0.028 & 0.026 & 12 & 70 \\
\hline \multirow[t]{2}{*}{ 2-Bu } & under vacuum & $9.3 \times 10^{-5}$ & $5.8 \times 10^{-5}$ & 38 & $3 \times 10^{4}$ \\
\hline & in air & $3.7 \times 10^{-5}$ & $2.2 \times 10^{-5}$ & 35 & $2 \times 10^{3}$ \\
\hline \multirow[t]{2}{*}{ OS-Ph } & under vacuum & $8.3 \times 10^{-5}$ & $6.5 \times 10^{-5}$ & 40 & $8 \times 10^{4}$ \\
\hline & in air & $5.0 \times 10^{-5}$ & $4.0 \times 10^{-5}$ & 65 & $1 \times 10^{3}$ \\
\hline \multirow[t]{2}{*}{ OS-EtH } & under vacuum & $5.5 \times 10^{-4}$ & $3.9 \times 10^{-4}$ & 63 & $5 \times 10^{5}$ \\
\hline & in air & $2.7 \times 10^{-5}$ & $2.7 \times 10^{-5}$ & 86 & $3 \times 10^{2}$ \\
\hline \multirow[t]{2}{*}{ OS-BuH } & under vacuum & $3.6 \times 10^{-3}$ & $2.7 \times 10^{-3}$ & 55 & $2 \times 10^{6}$ \\
\hline & in air & $7.3 \times 10^{-4}$ & $6.0 \times 10^{-4}$ & 68 & $4 \times 10^{4}$ \\
\hline OS-EtMe & under vacuum & $3.4 \times 10^{-5}$ & $2.1 \times 10^{-5}$ & 59 & $5 \times 10^{2}$ \\
\hline \multirow[t]{2}{*}{ OS-PrMe } & under vacuum & 0.019 & 0.015 & 65 & $6 \times 10^{6}$ \\
\hline & in air & $4.3 \times 10^{-3}$ & $2.4 \times 10^{-3}$ & 81 & $5 \times 10^{5}$ \\
\hline \multirow[t]{2}{*}{ OS-BuMe } & under vacuum & 0.024 & $9.6 \times 10^{-3}$ & 55 & $2 \times 10^{5}$ \\
\hline & in air & $1.3 \times 10^{-3}$ & $8.7 \times 10^{-4}$ & 94 & $2 \times 10^{4}$ \\
\hline \multirow[t]{2}{*}{ OS-PrEt } & under vacuum & 0.013 & 0.010 & 45 & $2 \times 10^{6}$ \\
\hline & in air & $7.1 \times 10^{-3}$ & $4.3 \times 10^{-3}$ & 78 & $5 \times 10^{5}$ \\
\hline
\end{tabular}

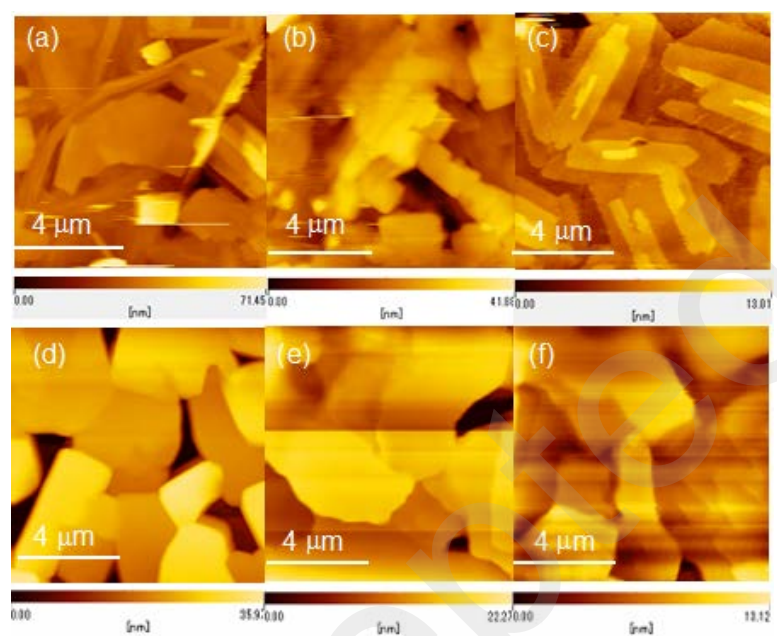

Fig. 8. Atomic force microscopic (AFM) images of (a) 1-Pr (b) 2-Et (c) OSBuH, (d) OS-EtMe, (e) OS-BuMe, and (f) OS-PrEt.
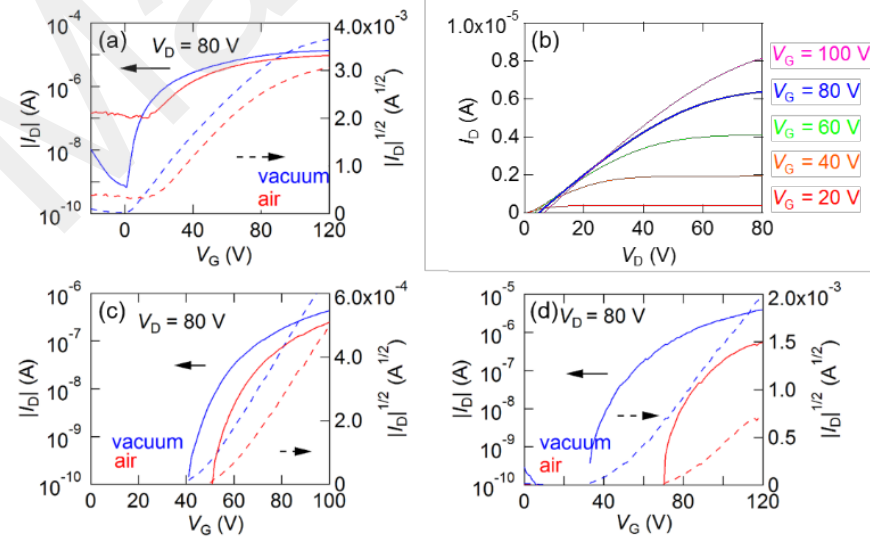

Fig. 9. (a) Transfer and (b) output characteristics of 2-Et thin-film transistors measured under vacuum (blue) and in air (red). Transfer characteristics of (c) OS-BuH, and (d) OS-PrEt.

\section{Transistor properties}

These compounds show n-channel transistor properties as exemplified by Fig. 9. From the characteristics, the transistor parameters are extracted as listed in Table 4. 2-Et shows maximum mobility of $0.041 \mathrm{~cm}^{2} \mathrm{~V}^{-1} \mathrm{~s}^{-1}$, which is not largely different from $0.15 \mathrm{~cm}^{2} \mathrm{~V}^{-1} \mathrm{~s}^{-1}$ in OS-Et. ${ }^{4}$ This transistor shows reasonable air stability. Although the off current increases considerably, the drop of the on current is not significant. As a result, the on/off ratio drops sometimes more than one order, but the mobility does not drop to half. Since mobilities of OS- $\boldsymbol{R}$ transistors drop typically four times in air, ${ }^{4}$ 
meaningful improvement of air stability is observed. In addition, although OS-R transistors show comparatively large threshold voltages, 2-Et exhibits a small threshold voltage. This is attributed to the drop of the LUMO levels from $-3.8 \mathrm{eV}$ to -4.2 $\mathrm{eV}$ due to the introduction of the quinoid structure (Table 1 ). The resulting LUMO level is as low as SS-R, although the air stability is not comparable to SS-R. The mobility of $\mathbf{O S}-\mathbf{P h}$ is not high, but the drop in air is comparatively small. This seems again to be associated with the relatively low LUMO level $(-3.95 \mathrm{eV})$ as well as the same type of molecular packing as SS- $\boldsymbol{R}$ (Fig. 4 ).

1-Ph shows transistor properties, but 1-Pr does not show transistor properties. This is ascribed to the very small intermolecular transfers (Fig. 2). However, the performance of the 1-Ph transistor decreases two orders of magnitude in air. This is reasonable in view of the high LUMO level $(-3.6 \mathrm{eV})$. We have also prepared $\mathbf{O S}-\mathbf{P h}$, but the transistor properties are not significant. This may be related to the stacking structure with extremely onedimensional interaction (Fig. 4).

Unsubstituted compounds, OS-EtH and OS-BuH, do not seem preferable to transistor performance. OS-BuH exhibits moderate transistor performance (Table 4), but the performance drops in air, reflecting the LUMO level of $-4.0 \mathrm{eV}$. In general, OS-PrMe, OS-BuMe and OS-PrEt show mobilities around $0.02 \mathrm{~cm}^{2} \mathrm{~V}^{-1} \mathrm{~s}^{-1}$. This is not as large as $0.15 \mathrm{~cm}^{2} \mathrm{~V}^{-1} \mathrm{~s}^{-1}$ in OSEt, but comparable to $0.05 \mathrm{~cm}^{2} \mathrm{~V}^{-1} \mathrm{~s}^{-1}$ in OS-Pr with similar $R$ length. ${ }^{4}$ This is also contrasting to the reduced performance of disordered OS-EtMe. Although the double layer structure does not significantly improve the mobility as unsymmetrical benzothienobenzothiophene (BTBT), ${ }^{19}$ it is important to maintain the ordered structure. Large threshold voltage is, however, unavoidable in OS-RR'. In this context, 2-Et shows a significant improvement.

\section{Conclusions}

We have prepared birhodanine molecules with extended $\pi$ skeletons. Compounds 2 with quinoid skeleton realize as strong acceptor ability as SS-R, and the air stability of the transistor performance and the threshold voltage are improved. Since the preparation of $\mathbf{O S}-\boldsymbol{R}$ is easier than SS- $\boldsymbol{R}$ in general, this is a versatile way to obtain an air-stable n-type material. In contrast, $\mathbf{1 - R}$ shows decreased acceptor ability and ( $\beta$ "-type) stacking structures with short-axis displacement. Together with OS-Ph and OS-BuH, this stacking structure resembles SS- $\boldsymbol{R}$ rather than the herringbone $\mathbf{O S}-\boldsymbol{R}$.

We have developed a method to prepare unsymmetrical OS$\boldsymbol{R} \boldsymbol{R}^{\prime}$, including $R=\mathrm{H}$ and $\mathrm{Ph}$, which are not accessible in the conventional method. $N$-H and $N$-Ph compounds show a slight improvement of the acceptor ability. The Z-form of OS-BuH is probably related to the contribution of hydrogen bond of the enolic form, and the enhanced S-S interaction is not too disadvantageous to the carrier transport despite the lowered symmetry. Basically, unsymmetrical OS-RR' has doublelayered herringbone structures, ${ }^{19}$ and the ordered structure achieves comparable transistor performance to the symmetrical OS-R.

\section{Conflicts of interest}

There are no conflicts to declare.

\section{Acknowledgements}

This work was partly supported by the JSPJ KAKENHI Grant Number 18H02044, and the Takahashi Industrial and Economic Research Foundation (08-003-022). The authors are grateful to Tokyo Institute of Technology Center for Advanced Materials Analysis for XRD measurement.

\section{Notes and references}

1 (a) Y. Zhao, Y. Guo and Y. Liu, Adv. Mater., 2013, 25, 5372; (b) L. Lu, T. Zheng, Q. Wu, A. M. Schneider, D. Zhao and L. Yu, Chem. Rev., 2015, 115, 12666; (c) J. T. E. Quinn, J. Zhu, X. Li, J. Wang and Y. Li, Y. J. Mater. Chem. C, 2017, 5, 8654.

2 (a) K. Takimiya, S. Shinamura, I. Osaka and E. Miyazaki, Adv. Mater., 2011, 23, 12604; (b) J. Cho, T. Higashino and T. Mori, Appl. Phys. Lett., 2015, 106, 193303.

3 A. Filatre-Furcate, T. Higashino, D. Lorcy and T. Mori, J. Mater. Chem. C, 2015, 3, 3569.

4 K. Iijima, Y. Le Gal, T. Higashino, D. Lorcy and T. Mori, J. Mater. Chem. C, 2017, 5, 9121

5 (a) N. Tenn, N. Bellec, O. Jeannin, L. Piekara-Sady, P. Auban-Sentier, J. Iniguez, E. Canadell and D. Lorcy, J. Am. Chem. Soc., 2009, 131, 16961; (b) G. Yzambart, N. Bellec, G. Nasser, O. Jeannin, T. Roisnel, M. Formigue, P. Auban-Sentier, J. Iniguez, E. Canadell and D. Lorcy, J. Am. Chem. Soc., 2012, 134, 17138.

6 K. Iijima, Y. Le Gal, D. Lorcy and T. Mori, RSC Adv., 2018, 8, 18400.

7 S. Ryo, D. Yoo, K. Iijima, R. Sato, Y. Le Gal, D. Lorcy and T. Mori, New J. Chem. 2019, 43, 11865.

8 H. Nagase, Chem. Pharm. Bull., 1973, 21, 279.

9 (a) G. Schukat and E. Fanghänel, Sulfur Report, 1996, 18, 1; (b) J. Yamada and T. Sugimoto, TTF Chemistry, 2004 Springer.

10 (a) Y. Yamashita, S. Tanaka, K. Imaeda and H. Inokuchi, Chem Lett. 1991, 20, 1231; (b) H. Fujimoto, K. Kamiya, S. Tanaka, T. Mori, Y. Yamashita and H. Inokuchi, Chem. Phys. 1992, 165, 135; (c) A. W. Addison, N. S. Dalal, Y. Hoyano, S. Huizinga and L. Weiler, Can. J. Chem., 1971, 55, 4191.

11 Y. Misaki, N. Higuchi, H. Fujiwara, T. Yamabe, T. Mori, H. Mori and S Tanaka, Angew. Chem. Int. Ed. Engl., 1995, 34, 1222.

12 (a) F. J. Allan, G. G. Allan and J. B. Thomson, Can. J. Chem., 1958, 36, 1579; (b) W. A. A. Arafa, R. M. Shakar and S. A. Rabeh, Heterocyc., 2016, 92, 1224; (c) V. Y. Horishny, L. Z. Mandzyuk, R. Z. Lytvyn, O. V. Bodnarchuk, V. S. Matiychuk and M. D. Obushak, Russ. J. Org. Chem., 2020, 56, 538.

13 R. Gompper, R. Kellner and K. Polborn, Angew Chem. Int. Ed. Engl., 1992, 31, 1202.

14 C. E. Redemann, R. N. Icke and G. A. Alles, Org. Synth. Coll. Vol., 1955, 3, 763.

15(a) C. A. Whitesitt, R. L. Simon, J. K. Reel, S. K. Sigmund, M. L. Phillips, J. K. Shadle, L. J. Heinz, G. A. Koppel, D. C. Hunden, S. L. Lifer, D. Berry, J. Ray, S. P. Lieele, X. Liu, W. S. Marshall and J. A. Panetta, Bioorg. Med. Chem. Lett., 1996, 6, 2157; (b) N. S. Cutshall, C. O'Day and M. Prezhdo, Bioorg. Med. Chem. Lett., 2005, 15, 3374; (c) K. Bourahla, A. Derdour, M. Rahmouni, F. Carreaux and J. P. Bazureau, Tetrahedron Lett., 2007, 48, 5785.

16 (a) R. M. Hann, J. Am. Chem. Soc., 1925, 47, 1189; (b) R. P. Rao, Chem. Ber. 1959, 92, 2600; (c) R. T. Pardasani, P. Pardasani, A. Jain and S. Kohli, Phos. Sulf. Silicon, 2004, 179, 1569.

17 M. L. Tang, A. D. Reicharrdt, P. Wei and Z. Bao, J. Am. Chem. Soc., 2009, 131, 5264.

18 ADF2017.109; Scientific Computing \& Modeling (SCM). Theoretical Chemistry; Vrije Universiteit: Amsterdam, The Netherlands., https://www.scm.com. 
19 (a) H. Iino, T. Usui and J. Hanna, Nat. Commun., 2015, 6, 6828; (b) S. Inoue, S. Shimahara, Y. Sadamitsu, S. Arai, S. Horiuchi, M. Yoneya, K. Takimiya and T. Hasegawa, Chem. Mater., 2018, 30, 5050. 